\title{
X-Ray of an Architectural Design
}

Studio: The Pendulum between the Ontology and Epistemology

OZAN AVCI

MEF University Faculty of Arts Design and Architecture 
Architectural design studio is a dynamic/interactive/productive atmosphere. This atmosphere is not limited to a physical space - like the school building - but can be produced collectively with the students where the educator comes together with them. Changing the atmosphere during the design process keeps students active, excited and motivated. This motivation triggers creativity. In order to support this creative atmosphere, a pendulum-like movement should be created between the ontology and epistemology of architecture through relational and critical thinking. At this stage, the design of the content and the process of the design studio by the educator come into prominence. In this paper the $x$-ray of a 3rd year undergraduate architectural design studio in Istanbul will be presented so as to discuss the interwoven relations between the educator, the content, the place, the students and the process.

The educator is the person who designs the architectural design studio. Therefore, how the theme and the place of the project is given by the educator has a critical role. The presented studio title is 'Rural aesthetics: Imaginative Landscapes + Seclusion + Unfamiliar Accommodation' at an abandoned quarry in Cappadocia, which is a natural and cultural heritage site in Turkey. An abandoned quarry is a provocative site, like a tabula-rasa in a rural context.

The content of the studio consists of discussions on rural aesthetics. Rural Aesthetics has two aspects: 'rural' is related with urban, nature, landscape, built/unbuilt environment, human/non-human and 'aesthetics' is related with experience, space-time-body relations, poetics and authenticity. These two aspects are discussed together with the mentioned concepts during the design process and the ontology and epistemology of architecture is examined through new ways of thinking, doing and representing. Three different design problematiques were introduced at the studio in the context of rural aesthetics. The first one was imaginative landscapes. Students make sketches of Cappadocian landscapes first and then make a sketch of their own imaginative landscape. This two-dimensional sketch is translated into a notational drawing, a 3D digital model and 4 different physical models (concrete, wooden, woven and 3D printed). The ontology of these representations and their epistemological reflections were discussed. To start the design studio process with a hands-on task is always increasing the level of enthusiasm of the students. The second design problematique was seclusion. Every student's thought on the concept of seclusion and designed a minimum space for themselves that will take place in their imaginative landscapes. This project allowed us to discuss and discover the relation between the body and space and the psychological needs of the human 
beings. The final design project was unfamiliar accommodation at the abandoned quarry in Cappadocia. In Cappadocia the traditional houses are masonry and the natural stones are taken from nearby quarries. As the region is a cultural and natural heritage site, the new buildings are expected to be masonry as well. This approach creates a dilemma at this point. Using the local stones makes the new buildings 'coherent' to the existing traditional neighborhoods, but the use of local stones creates new quarries where nature is heavily destroyed. Unfamiliar accommodation aims to bring life back to the quarry. Being unfamiliar has two aspects here: one is being unfamiliar to the neighborhood and create your own context there, and the other is making the accommodation unfamiliar by rethinking the ontology of such buildings.

The place of the design studio is both our studio place in our school building and the site itself. A filed trip was organized to Cappadocia and the region was experienced together with the students. The project site was measured by the students in order to make a scaled map of it. The bodily experience of such a big abandoned quarry is unique and to discuss about the project on-site is quite useful and inspiring.

The student is an active member of the design studio. $\mathrm{He} /$ she is responsible for raising new questions and proposing new possibilities for the given design problematiques. The educator can be a provocateur or a mediator, but the student should decide on his/her own. The design studio is like a research lab, so the educator and the students work together so as to investigate new spatial proposals, new ontologies and to discuss the given concepts epistemologically. Every design proposal is a new statement for architecture.

The process of the design studio is designed so as to trigger creativity through relational and critical thinking. In order to do that various sequences were designed such as field trips, lectures on philosophy and geography, workshops from other disciplines (weaving and typography), jury sessions, readings, writings, discussions, collective and individual works. 
ঠ

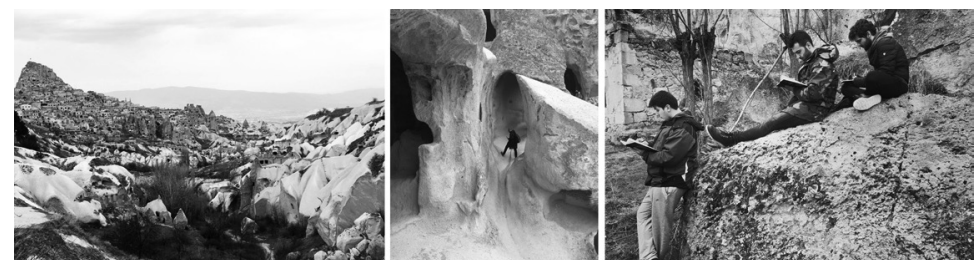

1: Cappadocia trip

$\overline{\mathrm{N}}$

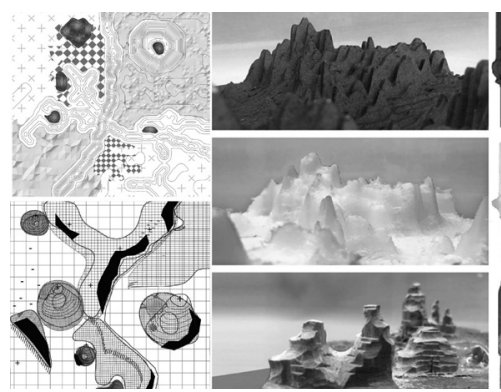

2: Imaginative Landscapes
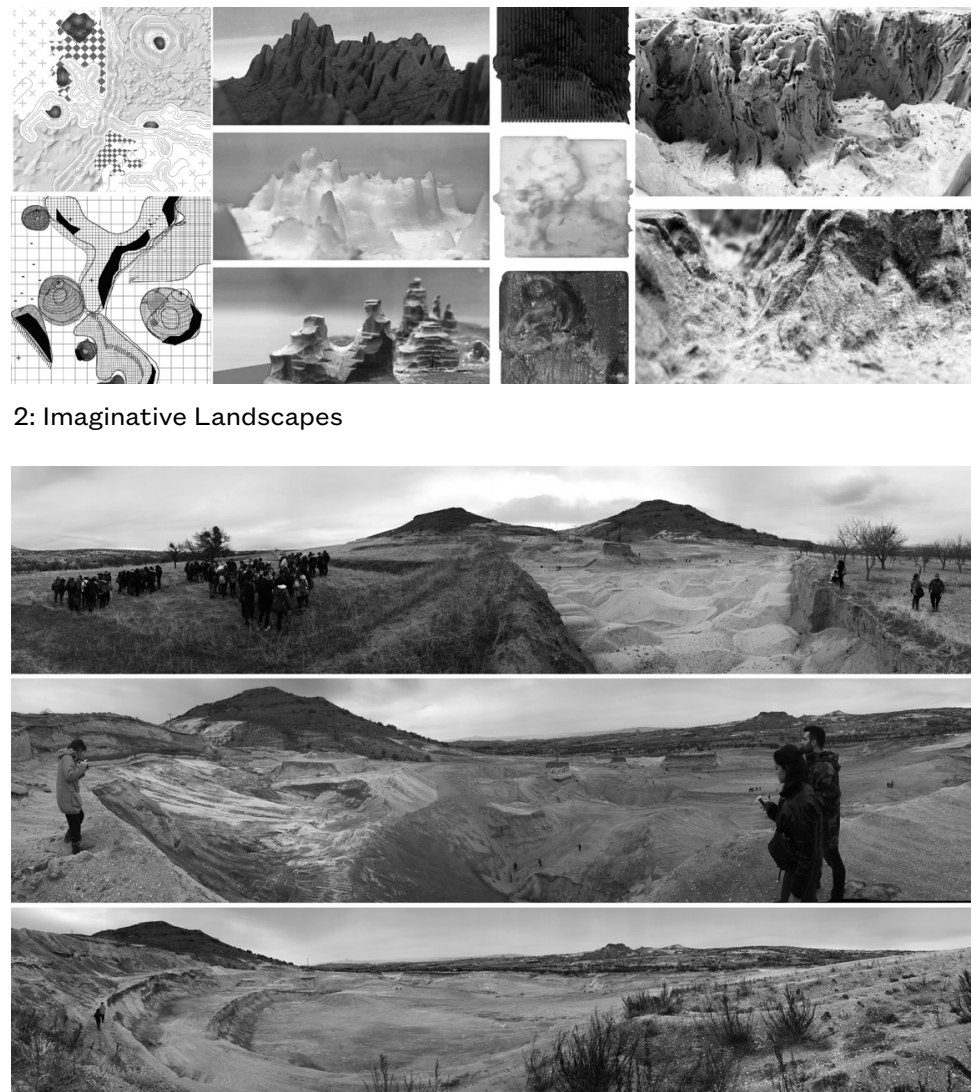

3: Site 


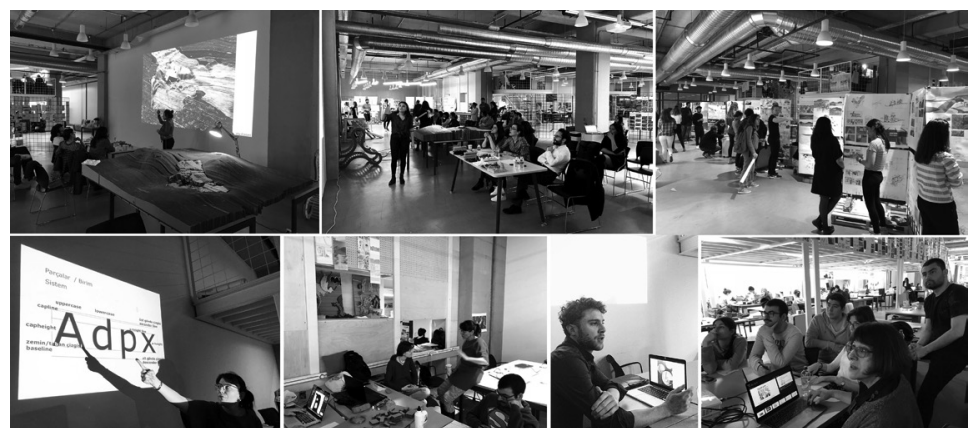

Studio Atmosphere
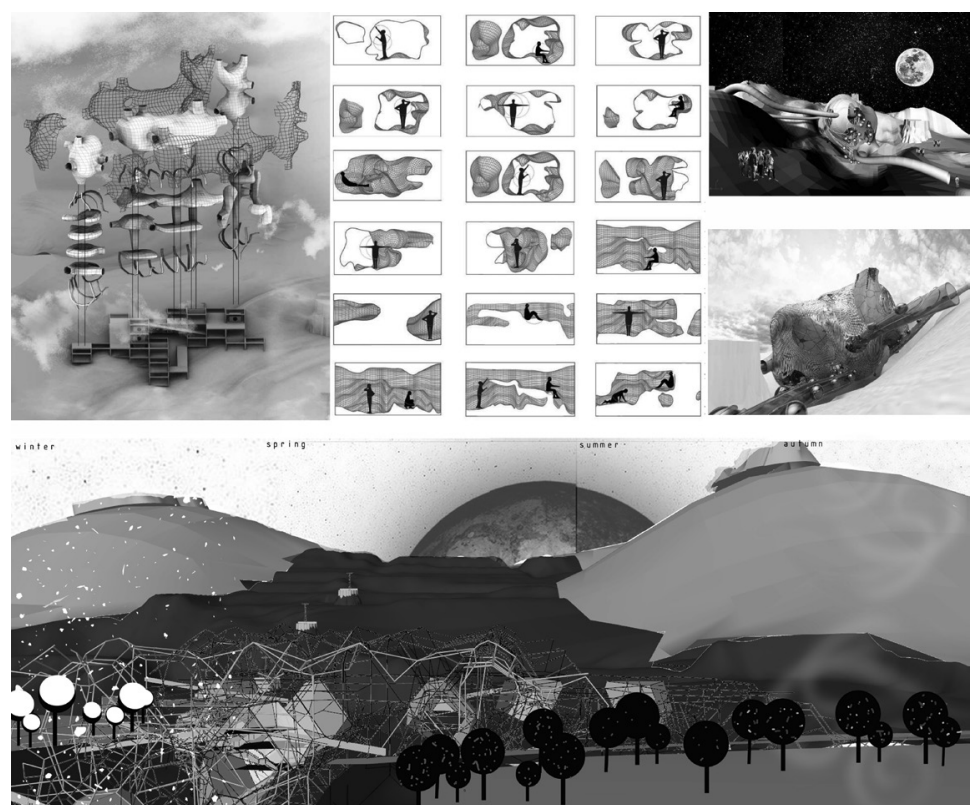

Unfamiliar Accommodation 
ত্ষ

$\stackrel{\infty}{N}$

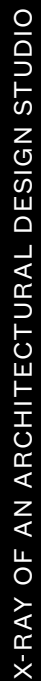

